\title{
Runner's Perceptions of Reasons to Quit Running: Influence of Gender, Age and Running-Related Characteristics
}

\author{
Daphne Menheere ${ }^{1, *}$, Mark Janssen ${ }^{1,2}{ }^{1}$, Mathias Funk ${ }^{1}{ }^{\circledR}$, Erik van der Spek ${ }^{1}$, \\ Carine Lallemand ${ }^{1,3}\left(\mathbb{D}\right.$ and Steven Vos ${ }^{1,2}$ (D) \\ 1 Department of Industrial Design, Eindhoven University of Technology, 5600 MB Eindhoven, The \\ Netherlands; mark.janssen@fontys.nl (M.J.); m.funk@tue.nl (M.F.); e.v.d.spek@tue.nl (E.v.d.S.); \\ c.e.lallemand@tue.nl (C.L.); s.vos@tue.nl (S.V.) \\ 2 School of Sport Studies, Fontys University of Applied Sciences, 5644 HZ Eindhoven, The Netherlands \\ 3 HCI Research Group, University of Luxembourg, Esch-sur-Alzette, 4365 Luxembourg, Luxembourg \\ * Correspondence: d.s.menheere@tue.nl
}

Received: 15 July 2020; Accepted: 18 August 2020; Published: 20 August 2020

\begin{abstract}
Physical inactivity has become a major public health concern and, consequently, the awareness of striving for a healthy lifestyle has increased. As a result, the popularity of recreational sports, such as running, has increased. Running is known for its low threshold to start and its attractiveness for a heterogeneous group of people. Yet, one can still observe high drop-out rates among (novice) runners. To understand the reasons for drop-out as perceived by runners, we investigate potential reasons to quit running among short distance runners (5 km and $10 \mathrm{~km})$ $(\mathrm{n}=898)$. Data used in this study were drawn from the standardized online Eindhoven Running Survey 2016 (ERS16). Binary logistic regressions were used to investigate the relation between reasons to quit running and different variables like socio-demographic variables, running habits and attitudes, interests, and opinions (AIOs) on running. Our results indicate that, not only people of different gender and age show significant differences in perceived reasons to quit running, also running habits, (e.g., running context and frequency) and AIOs are related to perceived reasons to quit running too. With insights into these related variables, potential drop-out reasons could help health professionals in understanding and lowering drop-out rates among recreational runners.
\end{abstract}

Keywords: running drop-out; novice runners; gender; age; running habits; attitudes; interests; motives

\section{Introduction}

Physical inactivity has become a major public health concern as it is associated with the development of chronic diseases [1,2]. Consequently, the awareness and importance of striving for an active and healthy lifestyle within our society have increased [3]. This is notably reflected in the increased popularity of unorganized recreational sports such as running $[4,5]$. Running is known for its low threshold to start: it is relatively inexpensive and easy to practice [6] and is associated with many health benefits (i.e., musculoskeletal and cardiovascular health, body composition, and psychological state) [7-14] and is therefore a popular recreational sport. This popularity is especially apparent in the increasing number of commercial running events, and their growing number of participants. In terms of event participation, running is even one of the most popular recreational sports in the world $[15,16]$. Therefore, since the begin of the 21st century, we can speak of the second wave of running [15].

The growing number and diversity of specialized running events (e.g., ladies runs, color runs, survival runs) are aligned with the development of the heterogeneous profile of 'the runner' over the years [17-19]. During the first wave of running starting in the 1960s, running used to be dominated by 
young males [20,21] as it was considered outrageous for women to engage in running [22]. It was not until almost 25 years later, the first Olympic marathon for women was introduced [15]. This partake of women in running continued to develop, where a strong growth is notably visible during the second wave of running, resulting in an almost equal distribution of men and women in recent years $[15,19,23]$. Similar to data of other Western countries [15], $11.3 \%$ of women and $13.2 \%$ of men within Dutch adults (i.e., the context of the present study), between the ages 20-79 years, expressed to run at least monthly in 2012 [23], also indicating the age diversity of running participants [15,24]. Besides some socio-demographic characteristics (i.e., gender and age) representing the heterogeneous population of runners, studies showed a variety in terms of motives to partake in running (e.g., health, social and competition elements, performance) $[4,25,26]$. Furthermore, one can also observe a broader range of different experienced runners (e.g., recreational, competitive) [27] but also running context (e.g., small groups, running partner, individually) $[4,19,28]$. This diverse profile of 'the runner' illustrates that running can appeal to many people (regardless of age, gender, motives, experience or running context) and illustrates the potential of making running even more accessible for an even larger group of people.

Despite the increasing popularity and the growing heterogeneity in runners, one can observe high drop-out rates due to running-related injuries and motivational loss, which is often noticeable among novice runners [29-31]. What type of runners are affected by running-related injuries and how this affects a potential drop-out, and how long this drop-out lasts, has been studied extensively in previous literature [29-33]. Although there is evidence on motivations to partake in running $[17,25,34,35]$, reasons to quit running are rather unexplored.

Previous studies on reasons to start running, show the influence of the different type of characteristics. Indicating the influence of socio-demographic variables (i.e., gender and age), running habits (e.g., experience, frequency, relative performance) and in the runners' attitudes, interests and opinions (AIOs). In a study of Hanson et al. women seemed to be more motivated by AIOs on weight concern, self-esteem, affiliation and psychological coping compared to men and less by AIOs with regards to competition and goal achievement [36]. This is in line with a study by Deaner et al., indicating men reported higher levels of competitiveness compared to women [37]. Motivational differences in age were investigated by Ogles and Masters, indicating young marathon participants (20-28 years) were more motivated by personal goal achievements, compared to older marathon runners ( $\geq 50$ years). Furthermore, the older participants were more motivated by weight concerns, life meaning, health orientation and affiliation. Besides gender and age, running experience also impacts AIOs towards running. For example, Forsberg et al. showed that more experienced runners, those who run for more than eight years, were more likely to run for social motives and just 'for the love of running'. Whereas lesser experienced runners, those who run up to three years were more health orientated.

Although motives for running can influence running drop-out [38-40], to the best of our knowledge, there is limited evidence about reasons to quit running. An important step toward expanding the evidence base is to understand the reasons for drop-out as perceived by runners. Hence, the scope of this paper is on the perceived reasons to quit running. Janssen et al. distinguish two groups of perceived reasons to quit running: individual (e.g., time management, injuries) and social (e.g., running partner/trainer quits) [4,41]. These reasons are covered by the items of the Leuven Running Survey 2009 [42] and adapted to event runners. Whether these are related to socio-demographic characteristics as gender and age, as they are for motives to running [17,36,37], or running-related characteristics is, however unknown.

With the present study, we aimed to: (i) gain insights in perceived reasons to quit running, and (ii) how this is affected by socio-demographics (i.e., gender and age) running habits, and AIOs on running. 


\section{Materials and Methods}

\subsection{Study Design and Respondents}

The data used in this study were drawn from the Eindhoven Running Survey 2016 (ERS2016). We collected data through an online standardized questionnaire among runners at the Eindhoven Marathon Running Event, which offered races at 5, 10, 21.1 and $42.2 \mathrm{~km}$. For this paper, a sub-dataset was drawn with only those runners that participated in the 5 and $10 \mathrm{~km}$ races. These distances were selected because of the heterogeneity of the participants, including both more experienced, less and unexperienced runners. The items used in this questionnaire were directly derived from the standardized questionnaire from previous editions of this event (ERS2014 and ERS2015).

In total, 18,261 runners participated in this event, who agreed upon registration that they could be contacted for research purposes. After finishing the event, all runners received an email with an explanation of the study, informed consent and our guarantee that their data would be processed anonymously. If they agreed upon participation in this study, they could click the link to the online questionnaire. The email contained all needed information and was in line with the ethical principles of the Declaration of Helsinki and the American Psychological Association. Thereby, the Research Board of the Fontys School of Sport Studies was consulted prior to initiation of this study, and approval for the study design was obtained.

Of the 18,261 runners, 3727 runners completed the questionnaire (overall response rate of 20.4\%) of which $7.9 \%$ in the $5 \mathrm{~km}$ and $16.2 \%$ in the $10 \mathrm{~km}$ run. Since this study focused on the 5 and $10 \mathrm{~km}$ distances, the subset used here consists of 898 runners (603 who ran the $10 \mathrm{~km}$ and 295 the $5 \mathrm{~km}$ ). The average age of the runners in the present study was 40.7 years, with the youngest runner at 18 years and the oldest 78 years old. $52.7 \%$ per cent of the participants were women ( $n=474$ runners). These socio-demographic backgrounds are comparable to other running samples in previous large-scale running studies in Western Europe [4,15,43].

\subsection{Questionnaire}

The online questionnaire consisted of three sections. The first section included attitudes, interests, and opinions (AIOs) on running, the second focused on socio-demographics and the last on running habits. The questionnaire is provided in the Supplementary Materials of a previous study of Janssen et al. (File S1, questionnaire ERS2016) [41], in which Figure S1 shows a flowchart of the questionnaire.

The first section of the questionnaire consists of items on running AIOs and was adopted from previous studies $[4,19,41,43]$. Runners were asked to rate the extent to which they agreed with the items, using a 5-point Likert scale (ranging from $1=$ totally disagree, to $5=$ totally agree). The second section of the questionnaire includes questions on sociodemographic characteristics. We asked for gender (male/female); age (years); professional status (student/unemployed/employed part-time/employed full-time); and level of education (lower and middle/higher/university). The third section covered running habits included running frequency (number of runs per week) years of running experience ( $<1$ year: novice; $1-5$ years: moderately experienced; $>5$ years: experienced); and preferred running context (individual/with friends/colleagues, small running groups/clubs).

\subsection{Measurements}

\subsubsection{Creating Scales of Running AIOs}

First, we created scales of the items on running AIOs by replicating the questionnaire used by Janssen et al. [41]. We ran reliability analyses for all scales. Items were assessed (Cronbach's Alpha's scores of $>0.700$ were considered acceptable) and reconsidered whether they substantively contributed to the component or not, and no changes were made. Finally, scales were constructed by calculating the average scores for the reliable items per component, resulting in average scale scores. Table 1 gives 
an overview of these components (i.e., scales), including the number of items, Cronbach's Alpha's and average score (ranging from 1 to 5). Eventually, five AIO-scales were formed and used in this study:

(1) Perceived advantages of running (e.g., 'running gives me energy', or 'running is good for my health');

(2) Identification with running (e.g., 'I am proud to be a runner', or 'I feel myself to be a real runner');

(3) Running is a sport that is easy to practice (e.g., 'I can practice running anytime, anywhere');

(4) Social motives for quitting (e.g., I would quit running 'if my trainer quit' or 'if my running friends quit');

(5) Individual motives for quitting (e.g., I would quit running if 'I got injured', or if 'my spare time was decreased').

Table 1. Components including the number of items, Cronbach $\alpha$, average scores and standard deviations.

\begin{tabular}{ccccccc}
\hline Scale & Attitudes toward Running & Items & Cronbach $\alpha$ & N & Mean & SD \\
\hline 1 & Perceived advantages of running & 4 & 0.794 & 853 & 4.29 & 0.458 \\
2 & Identification with running & 5 & 0.738 & 853 & 3.33 & 0.640 \\
3 & Running as a sport that is easy to practice & 3 & 0.781 & 853 & 4.22 & 0.623 \\
4 & Social motives for quitting & 3 & 0.941 & 853 & 1.79 \\
5 & Individual motives for quitting & 4 & 0.712 & 853 & 3.33 \\
\hline
\end{tabular}

\subsubsection{Dependent Variables}

In this study, we used two dependent variables: social motives for quitting and individual motives for quitting. As they do not follow a normal distribution, both scales were recoded into binary variables. All scores below the scale average (i.e., $M=1.79$ ) were coded as ' 0 below' and all scores above the average were coded as ' 1 above'. In this way, we were able to interpret the data relative to the sample and able to see if there are variables that could explain why runners score lower or higher compared to their fellow runners.

\subsubsection{Independent Variables}

As independent variables, we included three groups of variables: (i) socio-demographic variables; (ii) running habits; and (iii) running AIOs. The socio-demographic characteristics included gender, age, and level of education. The group of running habits consisted of variables that are directly related to running and which define the level of running involvement: years of running experience, training frequency and running context. The three-remaining scale on running AIOs perceived advantages of running, identification with running and running as a sport that is easy to practice complete the list of independent variables. Table 2 gives the descriptive statistics of the sample for the dependent and independent variables.

\subsection{Analysis}

All results were analyzed using SPSS 26.0 (IBM Corp., Armonk, NY, USA). First, descriptive statistics (i.e., mean scores, standard deviations, minimum and maximum values) were collected to provide an overview of the sample structure, and the items and variables used. Second, two binary logistic regression models (method = enter) were created with the two dependent variables: social motives for quitting and individual motives for quitting. As aforementioned, both scales were recoded into binary variables. Nagelkerke $R^{2}$ was used as a measure of goodness of fit. Values between 0.10 and 0.20 were considered as satisfactory and above 0.20 as very satisfactory $[44,45]$. The different models were tested for multicollinearity, outliers, and leverage points by calculating the variance inflation factors and influence statistics (Cook's). No problems with the data were found concerning these aspects. 
Table 2. The descriptive statistics of the sample for the dependent and independent variables.

\begin{tabular}{cccc}
\hline Variable & Measurement & $\mathbf{n}$ & $\mathbf{\%}$ \\
\hline \multirow{2}{*}{ Individual Motives Binary } & Below & 399 & 46.8 \\
& Above & 454 & 53.2 \\
\hline \multirow{2}{*}{ Social Motives Binary } & Below & 390 & 45.7 \\
& Above & 463 & 54.3 \\
\hline \multirow{2}{*}{ Gender } & Male & 387 & 47.8 \\
& Female & 422 & 52.2 \\
\hline \multirow{2}{*}{ Age } & $\leq 35$ year & 261 & 32.1 \\
& $36-45$ year & 239 & 29.4 \\
Education & $\geq 46$ year & 313 & 38.5 \\
& Lower or middle education & 273 & 33.5 \\
Experience & Higher education & 332 & 40.8 \\
& University & 209 & 25.7 \\
\hline \multirow{2}{*}{ Running frequency } & $<1$ years & 248 & 29.2 \\
& $1-5$ years & 364 & 42.8 \\
& $>5$ years & 238 & 28.0 \\
\hline \multirow{2}{*}{ Running context } & $\leq 1$ x/week & 384 & 45.1 \\
& 2x/week & 350 & 41.1 \\
& $\geq 3 x /$ week & 117 & 13.7 \\
\hline
\end{tabular}

\section{Results}

\subsection{Descriptive Analysis}

First, descriptive analysis shows that the social motives for quitting scores an average of 1.79 $(\mathrm{SD}=0.72)$ on a 5-point Likert scale. From the 853 runners, $390(45.7 \%)$ runners score below the group average, and the remaining $54.3 \%$ scores above and perceive relatively more social reasons to quit running. For the individual motives for quitting a mean of $3.33(\mathrm{SD}=0.78)$ on a 5-point Likert scale was given. Here, of the 853 runners, 399 (46.8\%) runners scored below this relative average, and the remaining $46.8 \%$ perceived relatively more individual reasons to quit running. In Table 3 , the mean scores on the items that form both scales are presented. If we compare these items, it is clear to see that 'physical constraints or injuries' are the most important reason to quit running $(\mathrm{M}=4.14 \mathrm{SD}=0.77)$, followed by item 6; 'tired of running' $(\mathrm{M}=3.20 ; \mathrm{SD}=1.05)$. The items that are related to 'social motives to quit running', score the lowest $(\mathrm{M}=1.82$ or lower).

Table 3. Mean scores, standard deviations, minimum and maximum values of the items.

\begin{tabular}{cccccc}
\hline Item No. & Item & Mean & SD & Min & Max \\
\hline 1 & My running partners quit running $^{1}$ & 1.82 & 0.85 & 1 & 5 \\
2 & My running group falls apart $^{1}$ & 1.80 & 0.84 & 1 & 5 \\
3 & My trainer/coach is leaving $^{1}$ & 1.76 & 0.80 & 1 & 5 \\
4 & Preference for another sport $^{2}$ & 3.06 & 1.04 & 1 & 5 \\
5 & Reduction of leisure time $^{2}$ & 2.95 & 1.05 & 1 & 5 \\
6 & Tired of running $^{2}$ & 3.20 & 1.06 & 1 & 5 \\
7 & Physical constraints or injuries $^{2}$ & 4.14 & 0.77 & 1 & 5 \\
\hline
\end{tabular}

Superscript number indicate to which scale, the items belong to. Social reasons to quit running indicated with a 1 , and individual reasons indicated with 2.

Second, the results of the binary logistic regression are presented in Table 4. The binary logistic regression with social motives for quitting running as a dependent variable showed significant 
differences ( $p<0.05, p<0.01$ or $p<0.001)$ for gender, experience with running, running context and on the AIOs towards running, viz. running as a sport that is easy to practice, perceived advantage of running and identification with running. The binary logistic regression with individual motives for quitting running as a dependent variable revealed significant differences for age, education level, experience with running, running frequency and one of the AIOs towards running, viz. identification with running.

Table 4. Results of the binary logistic regression, in odds ratios $(\operatorname{Exp}(\beta))$ with regards to the reference group (ref.).

\begin{tabular}{|c|c|c|c|}
\hline & & Social Reasons $(n=803)$ & Individual Reasons $(n=803)$ \\
\hline Constant & & $646,050 * * *$ & $42,827^{* * *}$ \\
\hline \multirow{2}{*}{ Gender } & Male & Ref. & Ref. \\
\hline & Female & $1.642 * *$ & 1.234 \\
\hline \multirow{3}{*}{ Age } & $\leq 35$ year & Ref. & Ref. \\
\hline & $36-45$ year & 1.018 & 0.777 \\
\hline & $\geq 46$ year & 1.402 & $0.498^{* * *}$ \\
\hline \multirow{3}{*}{ Education } & Lower or middle education & Ref. & Ref. ${ }^{* * *}$ \\
\hline & Higher education & 1.193 & $2.012 * * *$ \\
\hline & University & 0.972 & $2.721 * * *$ \\
\hline \multirow{3}{*}{ Experience } & $<1$ years & Ref. & Ref. \\
\hline & $1-5$ years & 0.829 & 0.888 \\
\hline & $>5$ years & $0.610 *$ & $0.610 *$ \\
\hline \multirow{3}{*}{ Running frequency } & $\leq 1 \mathrm{x} /$ week & Ref. & Ref. \\
\hline & 2x/week & 0.717 & 0.654 * \\
\hline & $\geq 3 x /$ week & 0.734 & 0.799 \\
\hline \multirow{3}{*}{ Running context } & Individual & Ref. $* * *$ & Ref. \\
\hline & Friends, colleagues, small groups & $3.352 * * *$ & 1.203 \\
\hline & Clubs & $4.541^{* * *}$ & 1.361 \\
\hline \multirow{3}{*}{ AIO toward running } & Running as a sport that is easy to practice & $0.502 * * *$ & 0.985 \\
\hline & Perceived advantages of running & $0.314^{* * *}$ & 0.992 \\
\hline & Identification & $1.366^{*}$ & $0.352^{* * *}$ \\
\hline Nagelkerke $\mathrm{R}^{2}$ & & 0.278 & 0.244 \\
\hline
\end{tabular}

\subsection{Binary Logistic Regression Social Reasons for Quitting}

In the model for 'social motives for quitting running', female runners were more likely ( $O R=1.642$; $p<0.01)$ to perceive social motives to quit running than male runners. No effect was found for age and education. With regards to the running habits, runners with more than 5 years of running experience, were less likely $(\mathrm{OR}=0.610 ; p<0.05)$ to perceive social motives to quit running compared to runners with less than 1 year of running experience. Thereby, runners who run with other runners are more likely to perceive social motives to quit running. Those who run with friends, colleagues and in small groups have an odds ratio of $3.352(p<0.001)$ and those who run in clubs have an odds ratio of 4.541 ( $p<0.01)$, both compared to runners that participate individually. The third running habit; running frequency did not show significant differences. In the final set of independent variables, significant differences for all included AIOs towards running were found. Those who see running as a sport that is easy to practice $(\mathrm{OR}=0.502 ; p<0.01)$ and those who perceive advantages of running $(\mathrm{OR}=0.314 ; p<0.01)$ were less likely to perceive social motives to quit running, whereas runners who identify themselves with running $(\mathrm{OR}=1.366 ; p<0.05)$ were more likely to perceive social motives to quit running.

\subsection{Binary Logistic Regression Individual Reasons for Quitting}

In the model for individual motives for quitting running, gender was not found to be associated with the individual motives, were the other socio-demographic variables was. Runners that were older ( $>46$ years) are less likely to perceive individual motives to quit running than younger runners $(<35$ years $)$ did $(\mathrm{OR}=0.498 ; p<0.001)$. Runners with higher education or who finished university, were 
more likely to quit running based on individual motives compared to runners with a lower of middle education (resp. $\mathrm{OR}=2.012 ; p<0.001$ and $\mathrm{OR}=2.721 ; p<0.001$ ). Similarly, to the model on social motives for quitting, runners with more than 5 years of running experience, were less likely $(\mathrm{OR}=0.610$; $p<0.05)$ to perceive individual motives to quit running compared to runners with less than 1 year of running experience. The running frequency was also found to be significant, those who run twice a week $(\mathrm{OR}=0.654 ; p<0.05)$ were less likely to perceive individual motives for quitting compared to runners who run once (or less) a week. Furthermore, runners who identify themselves with running $(\mathrm{OR}=0.352 ; p<0.001)$ were less to perceive individual motives to quit running. No significant differences were found for running context, and AIO-items running as a sport that is easy to practice and perceived advantages of running.

\section{Discussion}

The aim of this study was to gain insight among short-distance event runners into the perceived reasons to quit running, and to identify how these reasons are affected by socio-demographics (i.e., gender and age), running habits and AIOs on running. This is an important step toward expanding the evidence base to understand the reasons for dropout as perceived by runners. This is key to support runners in continued running and to address the barriers runners perceive adequately. The limitations of this study, such as the treatment of the data and its implications, are discussed at the end of the discussion section.

Our findings show that runners are more likely to perceive individual reasons to quit running than social reasons (Table 3). Physical constraints or injuries (item 7) is the most important reason to quit running, which is in line with previous studies [29-33], followed by being tired of running (item 6). Socials reasons to quit running because 'my trainer is leaving', or 'my buddy quit running' were less likely to be perceived as important. A possible explanation for this might be that a large group of the participants (approx. 60\%) does not run in a social context but runs individually. This is in line with studies showing that running is an activity that is mostly practiced individually, outside the organized context of clubs $[4,28,46]$. For individual runners, individual reasons to quit running might be more applicable and easier to identify with, as compared to social reasons.

For individual reasons to quit running, significant differences were found for age, education level, experience with running, running frequency and one of the AIOs towards running; identification with running (Table 4). Furthermore, results showed that social reasons to quit running are significantly different depending on the gender, experience with running, running context and on the AIOs towards running; running as a sport that is easy to practice, perceived advantage of running and identification with running.

Compared to male runners, our results show that female runners perceive more social reasons to quit running. This result may be explained by the fact that women appear to attach greater value to social support [47-49]. A previous study by Vos et al. [19], in which a typology of female runners was constructed, did show that women valued connectedness with others. This finding was also reported by Pridgeon and Grogan [49], stating that loss of social support contributed to exercise dropout, especially among women. Another possible assumption would be that female runners, compared to male runners, run more often in a social context and therefore experience social reasons to quit running more often. However, this explanation is not supported by a previous study $(\mathrm{N}=3727)$ on running typologies, which does not suggest that women are more likely to run in social contexts but often run in individual context as well [41]. Notably, in the present study, we did not found significant differences for individual reasons to quit running for gender. So, although female runners run in both social and individual contexts, social reasons to quit running are perceived more often by women than men.

Runners aged above 45 years, perceive fewer individual reasons to quit running as compared to younger runners below 35 years. This result might hint at the idea of people feeling more in control of their own time when ageing, as compared to having difficulties in seeking a way to incorporate running in their daily lives $[47,48,50]$. This might also be related to the fact that people over 45 are in a 
less exploratory phase of their lives, and thus do not perceive reasons to seek for different types of sports to practice [50]. Another explanation might be that these 'older' runners are more experienced and therefore, more aware of their bodies and potential injuries [30,51]. This is in line with a previous study, indicating that the most experienced runners included most runners being older than 45 [41]. What is notable is that there is no significant difference found for social reasons to quit running for age, indicating that reasons to quit from a social perspective are not dependent on age.

Our results suggest that runners who have a higher education or university degree perceive more individual reasons to quit running compared to runners with a low or middle educational degree. Runners with a university degree perceive these reasons about three times as much, and runners with a higher education twice as much. This is not the case for social reasons to quit running. The reason for this might be that runners with a higher or university degree have more trouble in finding a good work-life-sports balance, and thus have more trouble in prioritizing running on a day to day basis.

Running experience influenced both social and individual reasons to quit negatively, where runners who run for more than 5 years perceive less (social and individual) reasons to quit as compared to runners running for less than a year. We can hypothesize that runners who already have been running for more than 5 years have already been able to overcome obstacles and barriers (e.g., injuries or motivational loss) throughout the years and kept pursuing running [30,51]. On the other hand, participants running for less than a year might have a lower self-efficacy, i.e., confidence in one's ability to overcome potential obstacles [52]. Another possible explanation is that experienced runners might feel more competent, and therefore are less afraid of getting injured or being dependent on external factors like a coach or a running group. A previous study, for instance, indicated that the more experienced runners ( $>7$ years) were more likely to run "for the love of running" [25], which might indicate that regardless of some obstacles, their love for running helps them overcome these.

When looking at running frequency, the results suggest that runners who run twice a week perceive fewer individual reasons to quit running as compared to runners who run once a week or less. Notably, this is not the case for social reasons to quit running, nor for runners who run three times a week or more. Although these runners who run twice a week have a higher time investment compared to runners who run once a week or less, they might be able to better incorporate this activity in their schedule on a weekly basis [39]. For those running $\leq 1$ per week, the involvement into running is lower, as compared to runners who dedicate to run twice a week. These 'occasional' runners might perceive more reasons to quit since they have not been able to commit to the sport that often on a training basis yet $[39,41]$. Additionally, a lower running frequency might also affect the feeling of competence or experience, which in turn might increase the fear of getting injured [30].

Although runners in our sample generally experienced more individual reasons to quit running, the running context positively influenced social reasons to quit running. Runners who run in a running group perceive more than three times as many social reasons to quit running compared to runners who run individual, and runners running at a running club more than four times as much. It might seem obvious that when one runs individually, fewer social reasons to quit can be observed. Interestingly though, individual runners do not perceive more individual reasons to quit running, as compared to social runners. Individual reasons to quit running might thus not be dependent on the running context but on other variables (e.g., age, running experience, running frequency) as stated in earlier studies [17,36,37].

Runners who do not think of running as a sport that is easy to practice, and do not perceive many advantages of running, perceive more social reasons to quit running. Instead of these advantages of running, these runners might value and need other AIOs (e.g., social support) to go running and therefore, experience more social reasons to quit running [49].

When one identifies as being a runner, our results indicate that this affects both social and individual reasons to quit running. Runners who identify themselves as a runner perceive more social reasons to quit running. This might indicate that runners who run in a social context (e.g., club or running group), identify themselves as being a 'real' runner and therefore might also depend more 
on their fellow runners (as a community) and social support. When for example a fellow runner quits, this might act as a trigger to quit running [49]. Contrary to this, runners who identify as being a runner perceive less individual reasons to quit running. A possible explanation might be that these are less likely to get tired of running, or running is their main sport. This is in line with previous studies indicating that runners who identify strongly with running are the more experienced, long-distance runners [41,43], hinting they might have been able to overcome these possible reasons to quit previously.

Based on our results, we argue that although we see significant differences related to gender in social reasons to quit running and significant ones related to age in individual reasons to quit running, these should not be considered conclusive. Our results showed that running characteristics (e.g., running experience, context, frequency, running AIOs) also influence one's perceived reasons to quit running. We thus contribute to knowledge on running dropouts by drawing a more accurate picture of the situation.

\section{Limitations}

Our study has some limitations. As part of our sampling strategy, we selected a subset of the dataset and included runners who participated in the 5 and $10 \mathrm{~km}$ distances of the running event. Through this, we purposively focused on novice and less experienced runners, who are more likely to drop-out. Although these runners might not be representative of all runners who perceive reasons to quit running, participants of large running events have been considered a representative selection of the broader recreational running community in previous studies [41,53].

In this study, we investigated runners' perceived reasons to quit running. By asking perceived reasons, this study relies on self-reported data and the perception of the participants. We do not know if these reasons would be an actual reason to quit running. However, knowing more about the perception of runners might indicate possible solutions or interventions to lower drop-out rates.

Finally, some methodological limitations related to the dependent variables should be mentioned. As aforementioned, we had to recode our two dependent variables into binary variables because both scales were not normally distributed. We thus lost some information about individual differences. Yet, we were able to interpret the data relativity to the sample. Second, we used 7 items to construct the 2 independent variables. Next to these seven possible reasons to quit running, there are other reasons why runners may quit running. Here we decided to build further on previous studies and hence could benefit from items which have an acceptable internal consistency.

\section{Conclusions}

Our survey study shows that although gender and age have shown significant differences in perceived reasons to quit running, these should not be considered conclusive. Our findings implicate that running characteristics (e.g., running experience, context, frequency, running AIOs) also influence one's perceived reasons to quit running. These insights could help policymakers to understand novice runners and their perceived reasons for a potential drop-out. This insight can be used to match public health policies to the motives and barriers of novice runners. Sports professionals (e.g., trainers and, coaches) could use this insight to lower drop-out rates among novice runners and eliminate potential perceived reasons to quit running.

Supplementary Materials: The following are available online at http://www.mdpi.com/1660-4601/17/17/6046/s1, File S1: Figure of Descriptive Statistics and File S2: Mean scores and SD of the Items.

Author Contributions: Conceptualization, D.M., M.J. and S.V.; methodology, M.J. and S.V.; formal analysis, M.J. and S.V., investigation, M.J. and S.V.; writing—original draft preparation, D.M., M.J.; writing—review and editing, D.M., M.J., M.F., E.v.d.S., C.L. and S.V. All authors have read and agreed to the published version of the manuscript.

Funding: This work is part of the project Nano4Sports which is financed by Europees Fonds voor Regionale Ontwikkeling Interreg Vlaanderen Nederland award number(s): 0271. 
Acknowledgments: We would like to thank the organization and the runners of the Marathon Eindhoven 2016, for their help and time to take part in our online survey. Without their involvement, this study would not have been possible.

Conflicts of Interest: The authors declare no conflict of interest.

\section{References}

1. Warburton, D.E.R.; Charlesworth, S.; Ivey, A.; Nettlefold, L.; Bredin, S.S.D. A systematic review of the evidence for Canada's Physical Activity Guidelines for Adults. Int. J. Behav. Nutr. Phys. Act. 2010, 7, 39. [CrossRef] [PubMed]

2. World Health Organization. World Health Statistics 2016: Monitoring Health for the SDGs Sustainable Development Goals; World Health Organization: Geneva, Switzerland, 2016; ISBN 9241565268.

3. Trost, S.; Blair, S.N.; Khan, K.M. Physical inactivity remains the greatest public health problem of the 21st century: Evidence, improved methods and solutions using the ' 7 investments that work' as a framework. Br. J. Sports Med. 2014, 48, 394-401. [CrossRef] [PubMed]

4. Janssen, M.; Scheerder, J.; Thibaut, E.; Brombacher, A.; Vos, S. Who uses running apps and sports watches? Determinants and consumer profiles of event runners' usage of running-related smartphone applications and sports watches. PLoS ONE 2017, 12, e0181167. [CrossRef] [PubMed]

5. Hulteen, R.M.; Smith, J.J.; Morgan, P.J.; Barnett, L.M.; Hallal, P.C.; Colyvas, K.; Lubans, D.R. Global participation in sport and leisure-time physical activities: A systematic review and meta-analysis. Prev. Med. (Baltim) 2017, 95, 14-25. [CrossRef]

6. Eime, R.M.; Sawyer, N.; Harvey, J.T.; Casey, M.M.; Westerbeek, H.; Payne, W.R. Integrating public health and sport management: SPORT participation trends 2001-2010. Sport Manag. Rev. 2015, 18, 207-217. [CrossRef]

7. Borgers, J.; Vanreusel, B.; Vos, S.; Forsberg, P.; Scheerder, J. Do light sport facilities foster sports participation? A case study on the use of bark running tracks. Int. J. Sport Policy 2016, 8, 287-304. [CrossRef]

8. Shipway, R.; Holloway, I. Health and the running body: Notes from an ethnography. Int. Rev. Sociol. Sport 2016, 51, 78-96. [CrossRef]

9. Grunseit, A.; Richards, J.; Merom, D. Running on a high: Parkrun and personal well-being. BMC Public Health 2017, 18, 1-11. [CrossRef]

10. Nezlek, J.B.; Cypryańska, M.; Cypryański, P.; Chlebosz, K.; Jenczylik, K.; Sztachańska, J.; Zalewska, A.M. Within-Person Relationships Between Recreational Running and Psychological Well-Being. J. Sport Exerc. Psychol. 2018, 40, 146-152. [CrossRef]

11. Pedisic, Z.; Shrestha, N.; Kovalchik, S.; Stamatakis, E.; Liangruenrom, N.; Grgic, J.; Titze, S.; Biddle, S.J.H.; Bauman, A.E.; Oja, P. Is running associated with a lower risk of all-cause, cardiovascular and cancer mortality, and is the more the better? A systematic review and meta-analysis. Br. J. Sports Med. 2020, 54, 898-905. [CrossRef]

12. van Iperen, L.P.; de Jonge, J.; Gevers, J.M.; Vos, S.B. Running-related demands and vigor in long-distance runners: The moderating role of resources and recovery. Curr. Psychol. 2020,1-15. [CrossRef]

13. Schoemaker, J.; van Genderen, S.; de Boer, W.I.J. Increased physical activity in preparation for a women-only mass participation sport event: A framework for estimating the health impact. Int. J. Environ. Res. Public Health 2020, 17, 98. [CrossRef] [PubMed]

14. Junior, L.C.H.; Pillay, J.D.; van Mechelen, W.; Verhagen, E. Meta-Analyses of the Effects of Habitual Running on Indices of Health in Physically Inactive Adults. Sport. Med. 2015, 45, 1455-1468. [CrossRef] [PubMed]

15. Scheerder, J.; Breedveld, K.; Borgers, J. Running across Europe: The Rise and Size of One of the Largest Sport Markets; Springer: New York, NY, USA, 2015; ISBN 1137446374.

16. State of the Sport-Part II: Running Industry Report. 2014. Available online: http://runinfinity.com/2014/06/ 2014-state-of-the-sport-part-ii-running-industry-report.html (accessed on 19 August 2002).

17. Ogles, B.; Masters, K. A Typology of Marathon Runners Based on Cluster Analysis of Motivations. J. Sport Behav. 2003, 26, 69.

18. Rohm, A.J. A mixed-method approach for developing market segmentation typologies in the sports industry. Sport Mark. Q. 2006, 15, 29-39.

19. Vos, S.; Walravens, R.; Hover, P.; Borgers, J.; Scheerder, J. Voor de pret of de prestatie? Typologieen van evenementenloopsters. Vrijetijdsstudies 2014, 32, 19-34. 
20. Scheerder, J.; Vanreusel, B.; Taks, M.; Renson, R. Social sports stratification in Flanders 1969-1999: Intergenerational reproduction of social inequalities? Int. Rev. Sociol. Sport 2002, 37, 219-245. [CrossRef]

21. Van Bottenburg, M. De Tweede Loopgolf; W.J.H. Mulier Instituut: 's-Hertogenbosch, The Netherlands, 2006.

22. Sosienski, S. Women Who Run; Seal Press: New York, NY, USA, 2006; ISBN 1580051839.

23. Hover, P.; van der Werff, H.; Breedveld, K. Rising Participation Rates, Shifting Segments. In Running across Europe. The Rise and Size of One of the Largest Sport Markets; Springer: New York, NY, USA, 2015; pp. 187-207.

24. Wilder, B. On the run: A Physician's perspective. J. Orthop. Sports Phys. Ther. 2014, 44, 731-732. [CrossRef]

25. Forsberg, P. Denmark: Running for the Sake of Running? A Profile and Segmentation of Danish Runners. In Running across Europe; Springer: New York, NY, USA, 2015; pp. 59-80.

26. Scheerder, J.; Vos, S.; Taks, M. Expenditures on sport apparel: Creating consumer profiles through interval regression modelling. Eur. Sport Manag. Q. 2011, 11, 251-274. [CrossRef]

27. Clermont, C.A.; Duffett-Leger, L.; Hettinga, B.A.; Ferber, R. Runners' Perspectives on "Smart" Wearable Technology and Its Use for Preventing Injury. Int. J. Hum. Comput. Interact. 2020, 36, 31-40. [CrossRef]

28. Hallmann, K.; Wicker, P. Consumer profiles of runners at marathon races. Int. J. Event Festiv. Manag. 2012, 3, 171-187. [CrossRef]

29. Videbæk, S.; Bueno, A.M.; Nielsen, R.O.; Rasmussen, S. Incidence of Running-Related Injuries Per $1000^{\circ} \mathrm{h}$ of running in Different Types of Runners: A Systematic Review and Meta-Analysis. Sport. Med. 2015, 45, 1017-1026. [CrossRef]

30. Kemler, E.; Blokland, D.; Backx, F.; Huisstede, B. Differences in injury risk and characteristics of injuries between novice and experienced runners over a 4-year period. Phys. Sportsmed. 2018, 46, 485-491. [CrossRef]

31. Junior, L.C.H.; Costa, L.O.P.; Lopes, A.D. Previous injuries and some training characteristics predict running-related injuries in recreational runners: A prospective cohort study. J. Physiother. 2013, 59, 263-269. [CrossRef]

32. Van Poppel, D.; Scholten-Peeters, G.G.M.; van Middelkoop, M.; Koes, B.W.; Verhagen, A.P. Risk models for lower extremity injuries among short and long distance runners: A prospective cohort study. Musculoskelet. Sci. Pract. 2018, 36, 48-53. [CrossRef]

33. Fokkema, T.; Hartgens, F.; Kluitenberg, B.; Verhagen, E.; Backx, F.J.G.; van der Worp, H.; Bierma-Zeinstra, S.M.A.; Koes, B.W.; van Middelkoop, M. Reasons and predictors of discontinuation of running after a running program for novice runners. J. Sci. Med. Sport 2019, 22, 106-111. [CrossRef]

34. Parra-Camacho, D.; González-Serrano, M.H.; González-García, R.J.; Moreno, F.C. Sporting habits of urban runners: Classification according to their motivation. Int. J. Environ. Res. Public Health 2019, 16, 4990. [CrossRef]

35. Parra-Camacho, D.; Dos Santos, M.A.; González-Serrano, M.H. Amateur runners' commitment: An analysis of sociodemographic and sports habit profiles. Int. J. Environ. Res. Public Health 2020, 17, 925. [CrossRef]

36. Hanson, N.; Madaras, L.; Dicke, J.; Buckworth, J. Motivational Differences between Half, Full and Ultramarathoners. J. Sport Behav. 2015, 38, 180.

37. Deaner, R.O.; Masters, K.S.; Ogles, B.M.; Lacaille, R.A. Marathon Performance as a Predictor of Competitiveness and Training in Men and Women. J. Sport Behav. 2011, 34, 325-342.

38. Mueller, F.F.; Tan, C.T.; Byrne, R.; Jones, M. 13 Game Lenses for Designing Diverse Interactive Jogging Systems. In Proceedings of the Annual Symposium on Computer-Human Interaction in Play, Amsterdam, The Netherlands, 15-18 October 2017; pp. 43-56.

39. Rocha, C.M.; Gratao, O.A. The process toward commitment to running-The role of different motives, involvement, and coaching. Sport Manag. Rev. 2017, 21, 459-472. [CrossRef]

40. Havenar, J.; Lochbaum, M. Differences in Participation Motives of First-time Marathon Finishers and Pre-Race Dropouts. J. Sport Behav. 2007, 30, 270.

41. Janssen, M.; Walravens, R.; Thibaut, E.; Scheerder, J.; Brombacher, A.; Vos, S. Understanding Different Types of Recreational Runners and How They Use Running-Related Technology. Int. J. Environ. Res. Public Health 2020, 17, 2276. [CrossRef]

42. Scheerder, J.; Boen, F. The Flanders Run! Social-scientific research on the market of running. In Vlaanderen Loopt! Sociaal-Wetenschappelijk Onderzoek Naar de Loopsportmarkt; Academia Press: Cambridge, MA, USA, 2010; ISBN 9038214847. 
43. Deelen, I.; Janssen, M.; Vos, S.; Kamphuis, C.B.M.; Ettema, D. Attractive running environments for all? A cross-sectional study on physical environmental characteristics and runners' motives and attitudes, in relation to the experience of the running environment. BMC Public Health 2019, 19, 366. [CrossRef]

44. Hosmer, D.W., Jr.; Lemeshow, S. Applied Logistic Regression; John Wiley: New York, NY, USA, 2000; ISBN 0471654027.

45. Menard, S. Applied Logistic Regression Analysis, 2nd ed.; Quantitative Applications in the Social Sciences No. 106; Sage Publications: Newbury Park, CA, USA, 2002; p. 111.

46. Stragier, J.; Vanden Abeele, M.; Marez, L. De Recreational athletes' running motivations as predictors of their use of online fitness community features. Behav. Inf. Technol. 2018, 37, 815-827. [CrossRef]

47. James, D.V.B.; Johnston, L.H.; Crone, D.; Sidford, A.H.; Gidlow, C.; Morris, C.; Foster, C. Factors associated with physical activity referral uptake and participation. J. Sports Sci. 2008, 26, 217-224. [CrossRef]

48. McArthur, D.; Dumas, A.; Woodend, K.; Beach, S.; Stacey, D. Factors influencing adherence to regular exercise in middle-aged women: A qualitative study to inform clinical practice. N. Engl. J. Med. 2014, 300, 1056-1057. [CrossRef]

49. Pridgeon, L.; Grogan, S. Understanding exercise adherence and dropout: An interpretative phenomenological analysis of men and women's accounts of gym attendance and non-attendance. Qual. Res. Sport. Exerc. Heal. 2012, 4, 382-399. [CrossRef]

50. Hickey, M.; Mason, S. Age and gender differences in particpation rates, motivators for, and barriers to exercise. Mod. Psychol. Stud. 2017, 22, 3.

51. Stoggl, T.; Wunsch, T. Biomechanics of Marathon Running. In Marathon Running: Physiology, Psychology, Nutrition and Training Aspects; Zinner, C., Sperlich, B., Eds.; Springer International Publishing: Cham, Switzerland, 2016.

52. Barz, M.; Lange, D.; Parschau, L.; Lonsdale, C.; Knoll, N.; Schwarzer, R. Self-efficacy, planning, and preparatory behaviours as joint predictors of physical activity: A conditional process analysis. Psychol. Heal. 2016, 31, 65-78. [CrossRef] [PubMed]

53. Breedveld, K.; Scheerder, J.; Borgers, J. Running across Europe: The way forward. In Running across Europe; Springer: New York City, NY, USA, 2015; pp. 241-264.

(C) 2020 by the authors. Licensee MDPI, Basel, Switzerland. This article is an open access article distributed under the terms and conditions of the Creative Commons Attribution (CC BY) license (http://creativecommons.org/licenses/by/4.0/). 